\title{
Epidemiology and control of tuberculosis in Victoria, a low-burden state in south-eastern Australia, 2005-2010
}

\author{
C. J. Lavender, ${ }^{\star \star}$ M. Globan, ${ }^{*}$ H. Kelly, ${ }^{\dagger \ddagger}$ L. K. Brown, ${ }^{\S}$ A. Sievers, ${ }^{*}$ J. A. M. Fyfe,* T. Lauer, $\$$ \\ D. E. Leslie*
}

* Mycobacterium Reference Laboratory, and †Epidemiology Unit, Victorian Infectious Diseases Reference Laboratory, North Melbourne, Victoria, ₹National Centre for Epidemiology and Population Health, Australian National University, Canberra, Australian Capital Territory, §Communicable Diseases Prevention and Control Unit, Victorian Government

Department of Health, Melbourne, Victoria, Australia

S U M M AR Y

SETTING: Victoria, Australia.

OBJECTIVE: To describe the epidemiology and control of tuberculosis (TB) in Victoria, 2005-2010.

DESIGN: Retrospective review of laboratory-confirmed TB in Victoria, 2005-2010. State TB reference laboratory records were matched with Department of Health notification records to obtain laboratory, demographic, clinical and treatment data.

RESULTS: The incidence of TB fell in the Australianborn population but increased overall, reflecting an increase in the proportion of overseas-born cases from $88.9 \%$ to $95.8 \%$ between 2005 and $2010(P=0.03)$. Patients from India and Viet Nam accounted for over one third of all cases. For overseas-born cases, the median time between arrival and diagnosis was 4 years. Half of all diagnoses were pulmonary disease, of which $45.4 \%$ were Ziehl-Neelsen smear-positive. Treatment was most commonly self-administered $(76.9 \%)$, and very few patients defaulted or failed treatment $(1.1 \%)$. Only $4.1 \%$ of cases were linked to another laboratory-confirmed case. Multidrug-resistant TB remained uncommon $(1.7 \%$ of cases).

CONCLUSIONS: TB in Victoria remains low by global standards and continues to overwhelmingly affect the overseas-born population. Current TB control strategies in Victoria are effective, but strengthened control in highburden countries will also improve TB control locally. KEY WORDS: TB; public health; policy
AUSTRALIA has one of the lowest rates of tuberculosis (TB) in the world, 1,2 but international travel and mass movement of people, combined with the natural history of TB, mean that the global burden of disease has implications for the control of TB locally. ${ }^{3}$ TB is a notifiable disease in all Australian states and territories. In 2010, there were 1327 notifications of TB Australia-wide and the national incidence was 5.9 per 100000 population. ${ }^{4}$ However, specific subgroups, such as Indigenous people and persons born overseas, have rates many times higher than those of nonIndigenous Australian-born people. ${ }^{1}$ The incidence of TB also varies according to jurisdiction, with Victoria, Australia's second most populous state, recording the second highest number of notifications $(n=431)$ and the second highest incidence $(7.8 / 100000) .4$ The number of TB notifications in Victoria rose during the decade from 1998 to 2007,5 and the number of cases of multidrug-resistant TB (MDR-TB) also increased over the same period. ${ }^{6}$ This rise in drug-susceptible and drug-resistant TB has significant implications for public health policy and planning.
TB control in Victoria is overseen by a centralised TB programme within the Victorian Department of Health (DoH). The key elements of this programme are as follows:

1 Migrant screening for active TB by chest X-ray (CXR) prior to arrival, including a requirement for visa applicants whose CXR suggests inactive TB to undergo follow-up on arrival in Australia (known as a TB undertaking), in accordance with the health requirement specified in the Migration Regulations 1994; ${ }^{7}$

2 Epidemiological surveillance, including collection of clinical and demographic data on all notified cases;

3 Contact tracing, including targeted screening of, and treatment for, latent TB among those people who have been in contact with a case, particularly in institutional settings such as schools, workplaces and hospitals;

4 Specialised TB clinics providing free diagnosis and treatment through a network of public hospitals; and

Correspondence to: David E Leslie, Mycobacterium Reference Laboratory, Victorian Infectious Diseases Reference Laboratory, Locked Bag 815, Carlton South, Victoria, Australia 3053. Tel: (+61) 39342 2610. Fax: (+61) 393422666. e-mail: david.leslie@mh.org.au

Article submitted 10 October 2012. Final version accepted 11 January 2013. 
5 Provision of laboratory services, including routine drug susceptibility testing (DST) and genotyping.

Reviewing the epidemiology of TB in Victoria is an important part of assessing the effectiveness of this approach. The last comprehensive longitudinal study of TB in Victoria analysed laboratory-confirmed cases notified in the 15-year period from 1990 to 2004. , $^{8}$ The aim of the present study was to investigate the demographic and clinical characteristics of laboratoryconfirmed cases of TB diagnosed in the 6-year period following the last review to determine whether the epidemiology of TB in Victoria had changed during that time and to consider how any shifts in the composition of Victoria's TB population might influence TB control in the future. State TB reference laboratory records were matched with DoH notification records to create a combined data set comprising laboratory, demographic and clinical information on all cases of laboratory-confirmed TB diagnosed in Victoria from 2005 to 2010.

\section{STUDY POPULATION AND METHODS}

\section{Study population and case definition}

Any person residing in Victoria with a new laboratoryconfirmed diagnosis of TB made by the Victorian Infectious Diseases Reference Laboratory (VIDRL) between 2005 and 2010, and who was notified to the Victorian DoH, was eligible for inclusion. The case definition for laboratory-confirmed TB was:

1 Isolation of Mycobacterium tuberculosis complex, excluding M. bovis var. bacille Calmette-Guérin (BCG) by culture, and/or

2 Detection of $M$. tuberculosis complex by nucleic acid amplification testing (NAAT), except where a positive result was likely to be due to previously treated disease or BCG vaccination.

Patients whose notifications were rejected by the $\mathrm{DoH}$ (for example, where the case was found to have been the result of laboratory contamination and/or the clinical presentation was not consistent with active TB disease) were excluded from the analysis.

Laboratory records were matched against $\mathrm{DoH}$ notification records by a computer-generated search using different combinations of the first two characters of family and given names, date of birth, sex and postcode. A combined data set comprising laboratory, demographic and clinical data was created for the study. In 70 cases where no match was identified, where a match was based on sex and date of birth only $(n=74)$ or where there were multiple matches for a single patient $(n=288)$, the records were matched manually to ensure accuracy. The total number of TB notifications was also provided by the DoH.

\section{Data analysis}

Where available, the following information was collected for each case: age, sex, postcode, specimen type, specimen site, culture result, microscopy result, polymerase chain reaction result, first-line DST results, country of birth, year of arrival (for overseas-born patients), Indigenous status, clinical manifestation, epidemiological classification, how the case was found, treatment administration, treatment length, treatment outcome and number of contacts screened.

Annual rates and age-specific rates were calculated using the mid-year estimates of the population in Victoria for each year published by the Australian Bureau of Statistics (ABS). ${ }^{10}$ As population data by country of birth at the state and territory level were only available for census years, rates in the Australian- and overseas-born populations were analysed in two 3-year groups, 2005-2007 and 2008-2010, using $2006^{11}$ and $2011^{12}$ census data, respectively. Region of birth was determined from the categories used by the ABS. ${ }^{11}$ Statistical analyses were performed using Microsoft Excel (Microsoft, Redmond, WA, USA) and Stata, version 10.0 (StataCorp, College Station, TX, USA). The $\chi^{2}$ test was used to compare proportions and the Mann-Whitney $U$ test was used to compare age distributions. Differences in rates were calculated assuming a Poisson distribution.

\section{Ethics}

The study was approved by the Melbourne Health Human Research Ethics Committee (project no. 2011.182).

\section{RESULTS}

There were 1837 laboratory-confirmed cases of TB in Victoria from 2005 to 2010, representing 80.5\% of all TB notifications during this period. The number and rate of laboratory-confirmed cases increased from 277 cases $(5.5 / 100000)$ in 2005 to 356 cases $(6.4 / 100000)$ in $2010(P=0.048$; Figure 1$)$. Total notifications and notification rates, which include cases identified on the basis of clinical and epidemiological information that are not laboratory-confirmed, also rose and peaked at 436 notifications (7.9/100 000) in 2010 (Figure 1).

\section{Distribution by age, sex and country of birth}

Half $(52.8 \%)$ of the cases were male and the median age of the patients was 32 years for both males (interquartile range [IQR] 32-52) and females (IQR 25-50). The age-specific rate showed a typical bimodal distribution, with peaks at ages 20-34 years and $\geqslant 75$ years (Figure 2). Only 49 cases were aged $<15$ years; the incidence in this group decreased from $1.7 / 100000$ in 2005 to $0.4 / 100000$ in 2010 $(P=0.005)$. 


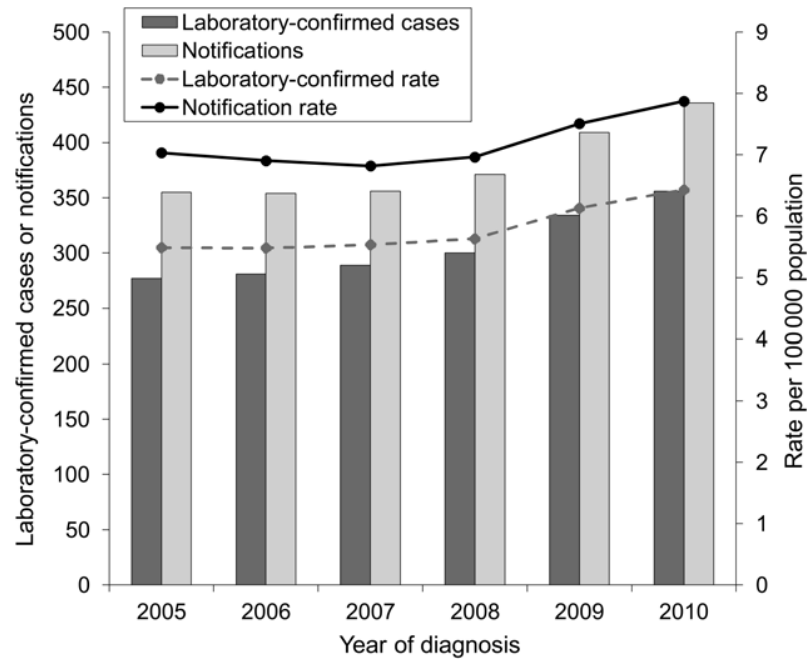

Figure 1 Laboratory-confirmed TB and all TB notifications, Victoria, 2005-2010. TB = tuberculosis.

Of the $1834(99.8 \%)$ cases for whom country of birth information was available, 1686 (91.9\%) were born overseas (Table 1). The proportion of overseasborn cases increased from $88.9 \%$ in 2006 to $95.8 \%$ in $2010(P=0.03)$. The number and rate of laboratoryconfirmed TB decreased in the Australian-born population, but increased in the overseas-born population. The average annual rate was 31 times higher in the overseas-born population than in the Australian-born population (Table 1).

With the exception of the $0-4$ year age group, where $11 / 16(68.8 \%)$ cases were Australian-born, overseas-born patients represented at least two thirds of cases in all age groups (Figure 2). The proportion of males and females was approximately equal for both Australian- and overseas-born cases, but the median age was slightly higher in Australian-born than in overseas-born patients ( 39 vs. 32 years, $P=0.08$ ). Only five $(3.4 \%)$ of the Australian-born cases were of Aboriginal and/or Torres Strait Islander origin.

\section{Overseas-born cases}

The highest proportion of overseas-born cases was born in Southern and Central Asia (38.6\%), with the number of patients from this region doubling during the study period (Figure 3). This increase was largely due to Indian-born patients, whose numbers rose from 53 in 2006 to 129 in 2010 (Table 1). Patients born in South-East Asia, almost half of whom were from Viet Nam, accounted for $28.6 \%$ of overseas-born cases. Patients born in Southern and Central Asia were much younger (median age 28 years) than patients born in Europe (median age 72 years; Figure 4).

The year of arrival was recorded for 1674 (99.3\%) overseas-born patients. The median time between arrival in Australia and diagnosis of TB was 4 years (IQR 2-14). A quarter of all cases were diagnosed within 2 years of arrival and two thirds within 10 years of arrival, although there was considerable variation according to region of birth (Figure 5). The median time between arrival and diagnosis was 2 years (IQR 1-5) for patients born in Southern and Central Asia compared with 41 years (IQR 30-51) for patients from Southern and Eastern Europe.

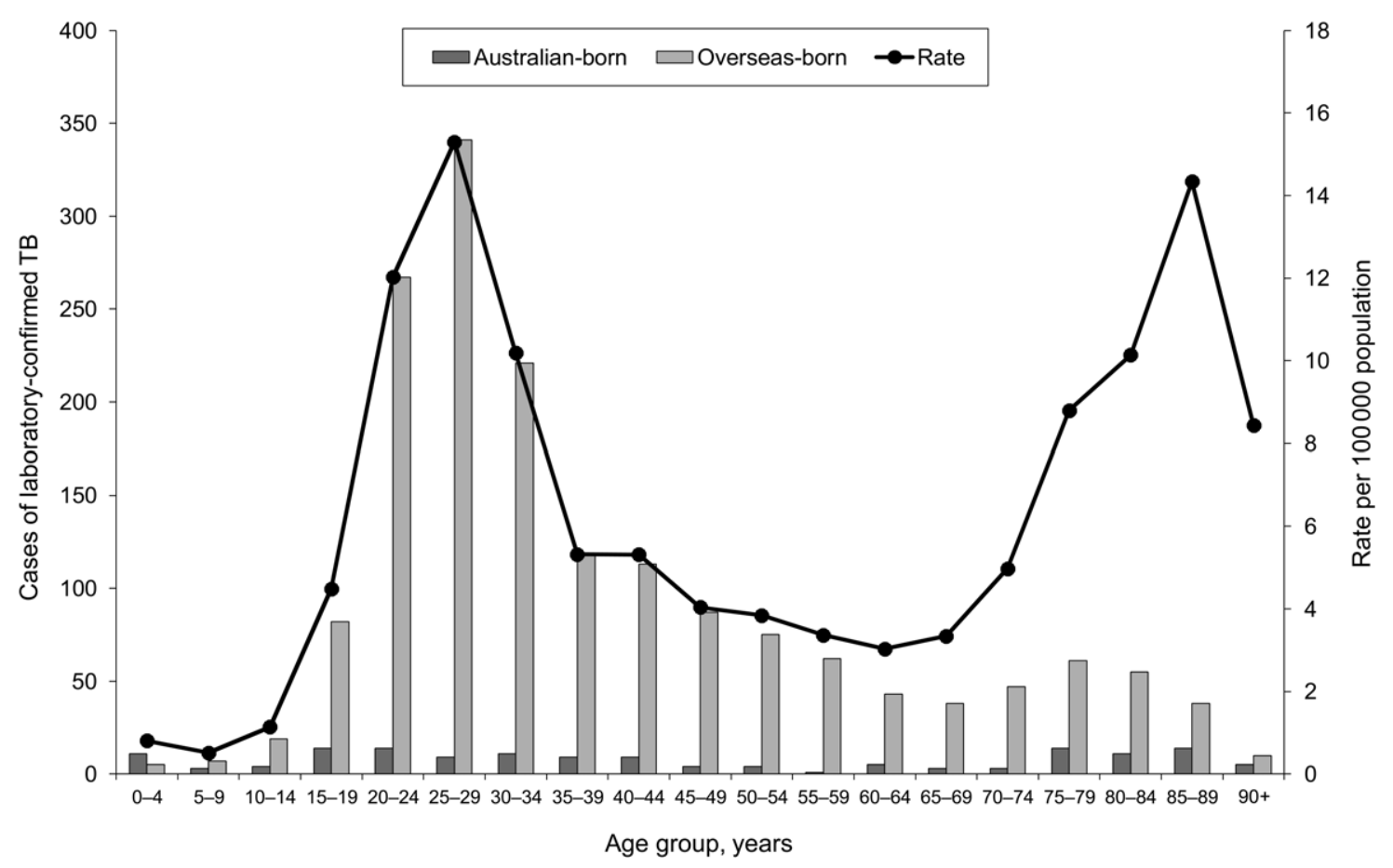

Figure 2 Laboratory-confirmed cases and laboratory-confirmed rates of TB by age group and Australian- versus overseas-born, Victoria, 2005-2010. TB = tuberculosis. 
Table 1 Laboratory-confirmed tuberculosis in Victoria, 2005-2010, by region and top 10 countries of birth

\begin{tabular}{|c|c|c|c|c|c|}
\hline \multirow[b]{2}{*}{ Country } & \multirow[b]{2}{*}{$\begin{array}{c}\text { Total cases } \\
n(\%)^{*}\end{array}$} & \multicolumn{2}{|c|}{ 2005-2007 } & \multicolumn{2}{|c|}{ 2008-2010 } \\
\hline & & $\begin{array}{c}\text { Average } \\
\text { annual } \\
\text { cases } \\
n \\
\end{array}$ & Rate $^{\dagger}$ & $\begin{array}{c}\text { Average } \\
\text { annual } \\
\text { cases } \\
n \\
\end{array}$ & Rate $^{\dagger}$ \\
\hline Australian-born & $148(8.1)$ & 27 & 0.8 & 22 & 0.6 \\
\hline Overseas-born & $1686(91.9)$ & 254 & 21.7 & 308 & 21.9 \\
\hline $\begin{array}{l}\text { Southern and } \\
\text { Central Asia } \\
\text { India } \\
\text { Nepal } \\
\text { Sri Lanka }\end{array}$ & $\begin{array}{c}650(35.4) \\
488(26.6) \\
43(2.3) \\
39(2.1)\end{array}$ & $\begin{array}{r}82 \\
62 \\
2 \\
6\end{array}$ & $\begin{array}{c}82.2 \\
117.3 \\
\overline{19.1}\end{array}$ & $\begin{array}{r}135 \\
101 \\
12 \\
7\end{array}$ & $\begin{array}{c}72.5 \\
90.1 \\
\overline{15.9}\end{array}$ \\
\hline $\begin{array}{l}\text { South-East Asia } \\
\text { Viet Nam } \\
\text { Philippines } \\
\text { Indonesia }\end{array}$ & $\begin{array}{c}483(26.3) \\
217(11.8) \\
90(4.9) \\
39(2.1)\end{array}$ & $\begin{array}{r}80 \\
38 \\
14 \\
7\end{array}$ & $\begin{array}{l}48.2 \\
65.1 \\
51.2 \\
55.5\end{array}$ & $\begin{array}{r}81 \\
34 \\
16 \\
6\end{array}$ & $\begin{array}{l}38.4 \\
49.8 \\
42.1 \\
39.0\end{array}$ \\
\hline $\begin{array}{l}\text { Sub-Saharan Africa } \\
\text { Somalia } \\
\text { Ethiopia }\end{array}$ & $\begin{array}{r}165(9.0) \\
60(3.3) \\
48(2.6)\end{array}$ & $\begin{array}{r}28 \\
10 \\
6\end{array}$ & $\begin{array}{l}61.5 \\
-\end{array}$ & $\begin{array}{l}27 \\
10 \\
10\end{array}$ & $\begin{array}{c}46.0 \\
- \\
-\end{array}$ \\
\hline North-East Asia & $123(6.7)$ & 22 & 24.0 & 19 & 14.0 \\
\hline China & $85(4.6)$ & 15 & 27.1 & 13 & 13.8 \\
\hline $\begin{array}{l}\text { North Africa and } \\
\text { the Middle East }\end{array}$ & $88(4.8)$ & 15 & 20.2 & 15 & 16.5 \\
\hline $\begin{array}{l}\text { Sudan } \\
\text { Southern and }\end{array}$ & $70(3.8)$ & 12 & - & 12 & - \\
\hline Eastern Europe & $83(4.5)$ & 14 & 4.7 & 14 & 5.1 \\
\hline $\begin{array}{l}\text { Oceania and } \\
\text { Antarctica }{ }^{\ddagger}\end{array}$ & $50(2.7)$ & 9 & 11.5 & 7 & 7.3 \\
\hline North-West Europe & $37(2.0)$ & 5 & 1.6 & 8 & 2.6 \\
\hline Americas & $7(0.4)$ & 1 & 1.7 & 2 & 3.4 \\
\hline
\end{tabular}

* Percentage of total cases where country of birth is known $(n=1834)$. † Average annual rate per 100000 population. Population data sourced from the Australian Bureau of Statistics 2006 census 11 and 2011 census. ${ }^{12}$ Population data were not available for patients born in Ethiopia, Nepal, Somalia or Sudan.

‡Excluding Australia.

\section{Clinical presentation, treatment} and epidemiological classification

Just over half of the diagnoses $(54.5 \%)$ were pulmonary disease. Microscopy results were available for $982(98.0 \%)$ of these patients, and $446(45.4 \%)$ were smear-positive. Australian-born cases had a higher proportion of pulmonary disease than overseas-born cases $(77.0 \%$ vs. $52.6 \%, P<0.001)$. The majority of cases $(89.7 \%)$ were found through clinical presentation, with a smaller number identified as part of a TB undertaking $(8.1 \%)$, DoH-initiated contact tracing $(1.5 \%)$ or other form of screening $(0.8 \%)$.

Information on treatment administration was available for 1659 (90.3\%) cases. First-line antituberculosis drugs were supplied free of charge as single-agent tablets. Treatment was most commonly self-administered on a daily basis $(76.9 \%)$. Other patients were supervised by a health care worker/family member/other $(21.5 \%)$, and $1.6 \%$ had treatment administered by directly observed therapy (DOT). Treatment outcome was recorded for 1697 (92.4\%) cases. Most patients $(88.6 \%)$ completed treatment, $4.9 \%$ died of TB or another cause, $4.1 \%$ transferred out of Australia and $1 \%$ were still under treatment. Only $20(1.1 \%)$ were described as having defaulted $(n=10)$, interrupted $(n=9)$ or failed $(n=1)$ treatment. The median time between commencement of standard first-line treatment and completion of treatment was 7 months (IQR 6-10).

For the 1837 laboratory-confirmed cases of TB diagnosed during 2005-2010, a combined total of 14599 contacts were screened. The average number of contacts screened per case was six and varied from zero for 847 cases to $>50$ for 38 cases. Only 76

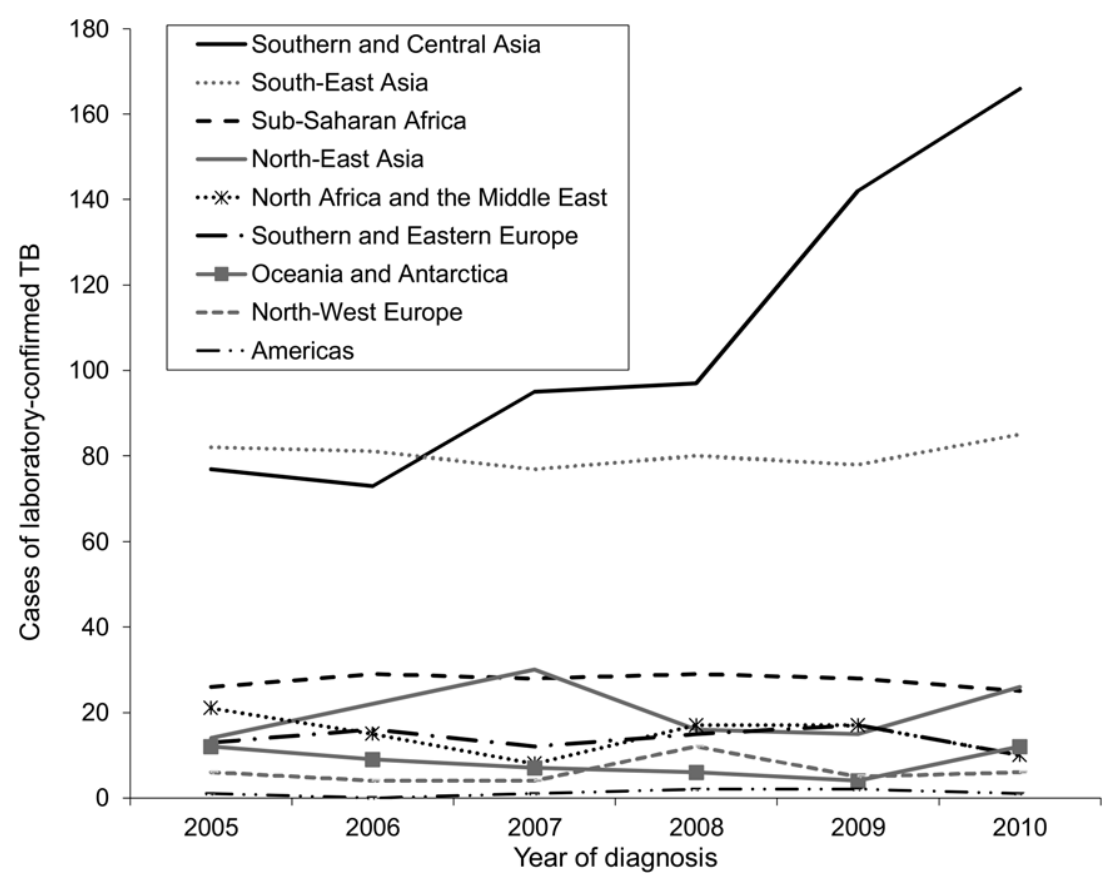

Figure 3 Overseas-born cases of laboratory-confirmed TB, Victoria, 2005-2010, by region of birth. TB $=$ tuberculosis. 


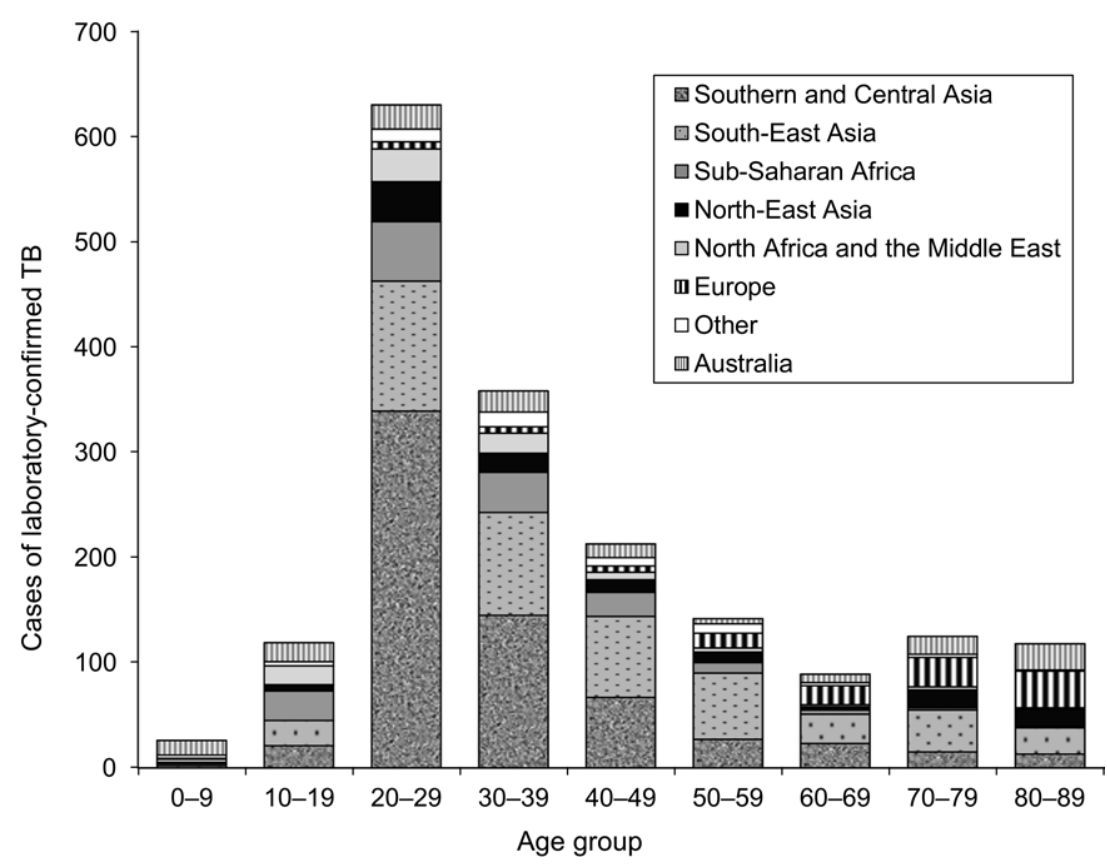

Figure 4 Laboratory-confirmed cases of TB by age group and region of birth, Victoria, 2005-2010. TB = tuberculosis.

$(4.1 \%)$ cases were recorded as being epidemiologically linked to a laboratory-confirmed case.

\section{Causative organism and drug resistance}

M. tuberculosis complex was isolated from 1763 $(96.0 \%)$ cases. Most $(99.1 \%)$ patients were infected with $M$. tuberculosis, with a small number of M. africanum $(n=4)$, M. bovis $(n=2)$, M. caprae $(n=1)$ and $M$. orygis (formerly known as oryx bacillus; $n=$ 8 ) identified. All eight patients infected with $M$. orygis were born in India, and all but one were female. The causative organism was not determined in 74
$(4.0 \%)$ patients where $M$. tuberculosis complex was identified using NAAT only. In 63 of these cases, culture was not performed (typically because fixed tissue specimens were received, prohibiting bacteriological investigation), and in 11 cases culture was performed but $M$. tuberculosis complex was not isolated.

DST results were available for all $1763 \mathrm{M}$. tuberculosis complex isolates for each of the first-line drugs, isoniazid (INH; $0.1 \mu \mathrm{g} / \mathrm{ml}$ and $0.4 \mu \mathrm{g} / \mathrm{ml}$ ), rifampicin (RMP), ethambutol (EMB) and pyrazinamide (PYZ; Table 2). A total of $159(9.0 \%)$ isolates were resistant to at least one first-line agent. Resistance to at

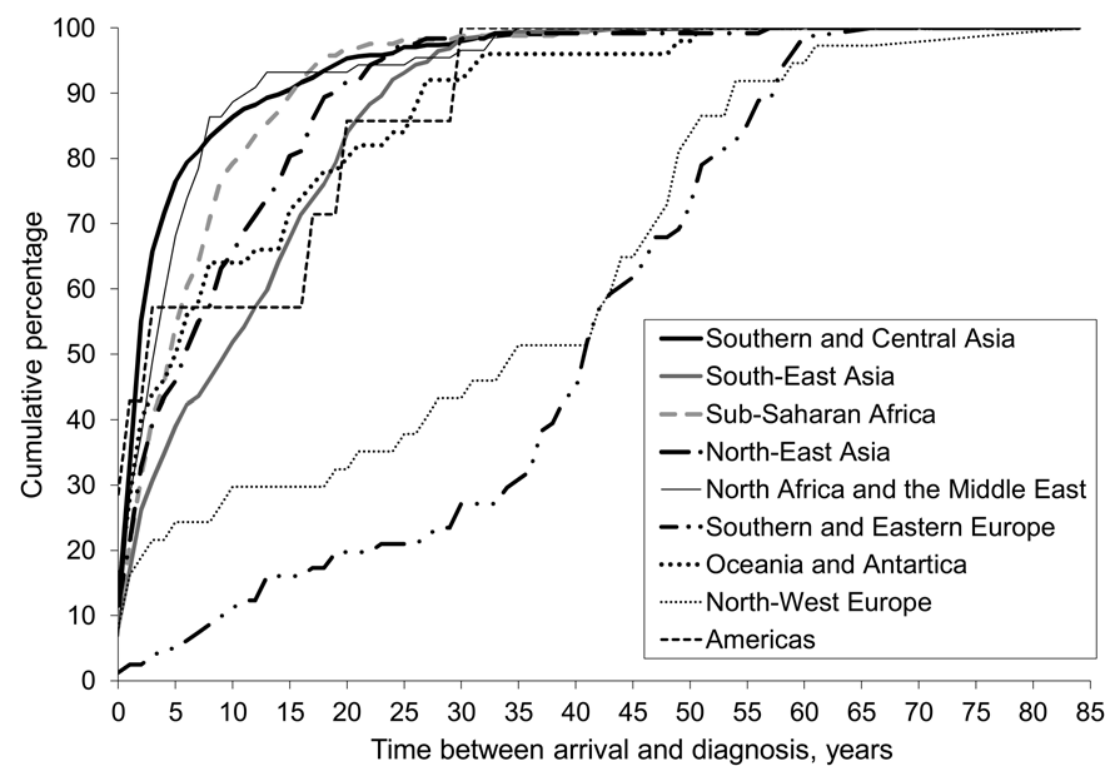

Figure 5 Cumulative percentage of years between arrival in Australia and diagnosis of laboratory-confirmed TB, Victoria, 2005-2010, by region of birth. TB = tuberculosis. 
Table 2 Drug resistance profiles of $M$. tuberculosis complex isolates, Victoria, 2005-2010*

\begin{tabular}{|c|c|}
\hline Resistance profile & Total \\
\hline Total isolates & 1763 \\
\hline Fully susceptible & 1604 \\
\hline \multicolumn{2}{|l|}{ Any resistance } \\
\hline INH & 153 \\
\hline $0.1 \mu \mathrm{g} / \mathrm{ml}$ & 43 \\
\hline $0.4 \mu \mathrm{g} / \mathrm{ml}$ & 110 \\
\hline RMP & 33 \\
\hline EMB & 9 \\
\hline PZA & 17 \\
\hline \multicolumn{2}{|l|}{ Monoresistance } \\
\hline INH & 120 \\
\hline $0.1 \mu \mathrm{g} / \mathrm{ml}$ & 40 \\
\hline $0.4 \mu \mathrm{g} / \mathrm{ml}$ & 80 \\
\hline RMP & 3 \\
\hline PZA & 3 \\
\hline \multicolumn{2}{|l|}{ Polyresistance } \\
\hline INH+EMB & 1 \\
\hline $\mathrm{INH}+\mathrm{PZA}$ & 1 \\
\hline $\mathrm{INH}+\mathrm{EMB}+\mathrm{PZA}$ & 1 \\
\hline \multicolumn{2}{|l|}{ Multidrug resistance } \\
\hline $\mathrm{NH}+\mathrm{RMP}$ & 16 \\
\hline $0.1 \mu \mathrm{g} / \mathrm{ml}$ & 1 \\
\hline $0.4 \mu \mathrm{g} / \mathrm{ml}$ & 15 \\
\hline $\mathrm{INH}+\mathrm{RMP}+\mathrm{EMB}$ & 2 \\
\hline $\mathrm{INH}+\mathrm{RMP}+\mathrm{PZA}$ & 7 \\
\hline $0.1 \mu \mathrm{g} / \mathrm{ml}$ & 2 \\
\hline $0.4 \mu \mathrm{g} / \mathrm{ml}$ & 5 \\
\hline $\mathrm{INH}+\mathrm{RMP}+\mathrm{EMB}+\mathrm{PZA}$ & 5 \\
\hline
\end{tabular}

* Isolates were resistant to $0.4 \mu \mathrm{g} / \mathrm{ml}$ INH unless otherwise indicated.

$\mathrm{INH}=$ isoniazid; RMP = rifampicin; EMB = ethambutol; PZA = pyrazinamide

least INH and RMP (MDR-TB) was detected in 30 $(1.7 \%)$ isolates. Of these, three strains were resistant to INH at $0.1 \mu \mathrm{g} / \mathrm{ml}$, but were susceptible at $0.4 \mu \mathrm{g} / \mathrm{ml}$ (low-level INH resistance). Five $(0.3 \%)$ isolates were resistant to all four first-line agents. There were no cases of extensively drug-resistant TB (XDR-TB).

\section{DISCUSSION}

This study demonstrates that, although there has been a gradual increase in the number and rate of laboratory-confirmed TB cases, the incidence of TB in Victoria remains low by global standards. TB in Victoria continues to be a disease that overwhelmingly affects the overseas-born population. Patients from South-East Asia, in particular Viet Nam, still represent a significant proportion of Victoria's TB cases, but their numbers are decreasing and they are getting older. ${ }^{8}$ Patients born in Southern and Central Asia, predominantly India, now account for the largest proportion of overseas-born cases. This shift in Victoria's TB population is a reflection of Australia's immigration patterns; ${ }^{13,14}$ between 2001 and 2011, the proportion of the Australian population born in India increased from $0.5 \%$ to $1.5 \%$, with similar large increases in immigration from Nepal, Bangladesh and Pakistan. This reinforces the previous observation that the most reliable predictor of TB incidence is the prevalence of TB in those countries from where migrants are accepted. ${ }^{15,16}$ Contact tracing demonstrated that, apart from isolated transmission events among household groups or other close contacts, transmission from migrants to the broader community was rare. As in other parts of Australia and similar lowincidence countries, most TB diagnoses in Victoria are thus due to reactivation of latent TB infection (LTBI) acquired in the patient's country of birth. ${ }^{3,15,17-21}$

The study has shown declining rates of TB in the Australian-born population, a very low proportion of patients defaulting from treatment, a low rate of drug resistance and a low level of local transmission. These findings demonstrate the effectiveness of the current TB service delivery model in Victoria, and confirm that supervised treatment in a dedicated TB control programme can give comparable results to universal DOT, while allowing greater flexibility for patients. However, increasing migrant intake from high TB burden countries means that this approach will not eliminate $\mathrm{TB}$ in Victoria. The expansion of the migrant screening programme to include testing for LTBI has previously been proposed, 8,9 but the detection and treatment of LTBI as a method of TB control in low-incidence countries is a complex issue that raises a number of ethical considerations, and the evidence on clinical outcomes and cost-effectiveness from other low-burden settings in Europe and North America is limited and contradictory. ${ }^{22-27}$ Nevertheless, a recent analysis found that it could be ethically justifiable to introduce screening for LTBI into the immigration process of Australia under certain circumstances. ${ }^{28}$

Increasing Australia's investment in global TB control is an alternative approach to reducing the impact of TB in Victoria, as it has been shown that industrialised countries gain most by supporting TB control programmes in their own jurisdictions and the rest of the world. ${ }^{23}$ One study suggested that USfunded efforts to expand the DOTS strategy in Mexico, Haiti and the Dominican Republic could reduce TB-related morbidity and mortality among migrants to the United States, producing net cost savings for the United States. ${ }^{29}$

The main strengths of this study were the completeness and accuracy of the data set. As TB is a notifiable disease in Victoria, case detection was high and, for most variables, the data set was near complete. Rigorous checking provided confidence in the accuracy of the data linkage. A limitation of the study was the availability of country of birth data for census years only, which prohibited calculation of annual incidence rates in each of the regional subgroups. The difficulties associated with compiling the data set for this study, which involved the linking of two databases and manual matching of hundreds of patient records, highlight one of the key barriers to undertaking this kind of analysis. The need for a single TB database in Australia that combines laboratory and notification data has long been recognised, but information 
technology limitations and differences between the states have hampered these efforts. 1,30

\section{CONCLUSIONS}

TB in Victoria remains low by global standards and continues to overwhelmingly affect the overseas-born population. Current TB control strategies are effective; however, as the epidemiology of TB in Victoria reflects migration patterns and the prevalence of TB in the country of origin of new arrivals, supporting strengthened TB control in high-burden countries from where migrants are accepted is likely to contribute to improved TB control locally.

\section{Acknowledgements}

The authors acknowledge the tuberculosis (TB) nurses at the TB Prevention and Control Programme, Victorian Government Department of Health, the specialist TB clinicians at the network of Victorian TB clinics and the scientists at the Victorian Mycobacterium Reference Laboratory, Victorian Infectious Diseases Reference Laboratory, for generating the notification, clinical and laboratory data used in this study. The authors also thank J Fielding for assistance with statistical analyses, P Johnson for helpful discussions and D Wilson for assistance with preparation of figures.

Conflict of interest: none declared.

\section{References}

1 Barry C, Waring J, Stapledon R, Konstantinos A. Tuberculosis notifications in Australia, 2008 and 2009. Commun Dis Intell 2012; 36: 82-94.

2 World Health Organization. Global tuberculosis control: WHO report 2011. WHO/HTM/TB/2011.16. Geneva, Switzerland: WHO, 2011. http://whqlibdoc.who.int/publications/2011/978 9241564380_eng.pdf Accessed February 2013.

3 National Tuberculosis Advisory Committee of Communicable Diseases Network Australia. National strategic plan for TB control in Australia beyond 2000. Canberra, ACT, Australia: National Tuberculosis Advisory Committee, 2002. http://www. health.gov.au/internet/main/publishing.nsf/content/cda-pubscdi-2002-cdi2602-cdi2602i.htm Accessed February 2013.

4 Milton A, Stirzaker S, Trungove M, et al. Australia's notifiable diseases status, 2010: annual report of the National Notifiable Diseases Surveillance System. Commun Dis Intell 2012; 35: $1-69$.

5 Barry C, Konstantinos A, National Tuberculosis Advisory Committee. Tuberculosis notifications in Australia, 2007. Commun Dis Intell 2009; 33: 304-315.

6 Lavender C J, Brown L K, Johnson P D. Multidrug-resistant tuberculosis in Victoria: a 10-year review. Med J Aust 2009; 191: 315-318.

7 Australian Government Department of Immigration and Citizenship. Fact sheet 22: the health requirement. Canberra, ACT, Australia: Department of Immigration and Citizenship, 2010.

8 McPherson M E, Leslie D, Sievers A, Patel M, Kelly H. Epidemiology of laboratory confirmed tuberculosis in Victoria, 1990 to 2004. Commun Dis Intell 2008; 32: 237-241.

9 McPherson M E, Kelly H, Patel M S, Leslie D. Persistent risk of tuberculosis in migrants a decade after arrival in Australia. Med J Aust 2008; 188: 528-531.

10 Australian Bureau of Statistics. 3101.0: Australian demographic statistics. Canberra, ACT, Australia: Australian Bureau of Statistics, 2012.

11 Australian Bureau of Statistics. 2006 Census of Population and
Housing Cat. No. 2068.0. Canberra ACT, Australia: Australian Bureau of Statistics, 2007.

12 Australian Bureau of Statistics. 2011 Census of Population and Housing. Canberra ACT, Australia: Australian Bureau of Statistics, 2011. http://www.abs.gov.au/websitedbs/censushome. nsf/home/data?opendocument\&navpos=200 Accessed March 2013.

13 Australian Bureau of Statistics. 4102.0-Australian social trends, December 2011. Canberra ACT, Australia: Australian Bureau of Statistics, 2011. http://www.abs.gov.au/AUSSTATS/ abs@.nsf/allprimarymainfeatures/573AD76DFABE2DFCCA2 579CE000BAD25?opendocument Accessed February 2013.

14 Australian Bureau of Statistics. 3412.0-Migration, Australia, 2009-10. Canberra ACT, Australia: Australian Bureau of Statistics, 2011.

15 Watkins R E, Plant A J. Predicting tuberculosis among migrant groups. Epidemiol Infect 2002; 129: 623-628.

16 Watkins R E, Plant A J, Gushulak B D. Tuberculosis rates among migrants in Australia and Canada. Int J Tuberc Lung Dis 2002; 6: 641-644.

17 Gallego B, Sintchenko V, Jelfs P, Coiera E, Gilbert G L. Threeyear longitudinal study of genotypes of Mycobacterium tuberculosis in a low prevalence population. Pathology 2010; 42: 267-272.

18 Jelfs P, Sintchenko V, Gilbert G L. Genotyping of Mycobacterium tuberculosis in New South Wales: results from 18 months of a statewide trial. NSW Public Health Bull 2006; 17: 81-85.

19 Littleton J, Park J, Thornley C, Anderson A, Lawrence J. Migrants and tuberculosis: analysing epidemiological data with ethnography. Aust NZ J Public Health 2008; 32: 142-149.

20 Department of Human Services. Management, control and prevention of tuberculosis: guidelines for health care providers (2002-2005). Melbourne, VIC, Australia: Victorian Government Department of Human Services, 2002.

21 Denholm J T, Leslie D E, Jenkin G A, et al. Long-term followup of contacts exposed to multidrug-resistant tuberculosis in Victoria, Australia, 1995-2010. Int J Tuberc Lung Dis 2012; 16: $1320-1325$.

22 Abubakar I, Stagg H R, Cohen T, et al. Controversies and unresolved issues in tuberculosis prevention and control: a lowburden-country perspective. J Infect Dis 2012; 205 (Suppl 2): S293-S300.

23 Klinkenberg E, Manissero D, Semenza J C, Verver S. Migrant tuberculosis screening in the EU/EEA: yield, coverage and limitations. Eur Respir J 2009; 34: 1180-1189.

24 Coker R, van Weezenbeek K L. Mandatory screening and treatment of immigrants for latent tuberculosis in the USA: just restraint? Lancet Infect Dis 2001; 1: 270-276.

25 Khan K, Muennig P, Behta M, Zivin J G. Global drug-resistance patterns and the management of latent tuberculosis infection in immigrants to the United States. N Engl J Med 2002; 347: 1850-1859.

26 Menzies D. Screening immigrants to Canada for tuberculosis: chest radiography or tuberculin skin testing? CMAJ 2003; 169: 1035-1036.

27 Schwartzman K, Menzies D. Tuberculosis screening of immigrants to low-prevalence countries. A cost-effectiveness analysis. Am J Respir Crit Care Med 2000; 161 (3 Pt 1): 780-789.

28 Denholm J T, McBride E S, Brown G V. Ethical evaluation of immigration screening policy for latent tuberculosis infection. Aust NZ J Public Health 2012; 36: 325-328.

29 Schwartzman K, Oxlade O, Barr R G, et al. Domestic returns from investment in the control of tuberculosis in other countries. N Engl J Med 2005; 353: 1008-1020.

30 Lumb R, Bastion I, Carter R, Jelfs P, Keehner T, Sievers A. Tuberculosis in Australia: bacteriologically confirmed cases and drug resistance, 2008 and 2009. A report of the Australian Mycobacterium Reference Laboratory Network. Commun Dis Intell 2011; 35: 154-161. 
CONTEXTE : Etat de Victoria, Australie.

OBJECTIF : Décrire l'épidémiologie et la lutte contre la tuberculose (TB) dans l'Etat de Victoria, 2005-2010.

SCHÉMA : Revue rétrospective des TB confirmées par le laboratoire dans l'Etat de Victoria, 2005-2010. On a apparié les enregistrements des laboratoires de référence de TB de l'Etat avec les dossiers de déclaration du Département de la Santé afin d'obtenir des données de laboratoire, des données démographiques, des données cliniques et de traitement.

RÉSULTATS : L'incidence de la TB a baissé dans la population née en Australie mais a augmenté au total, ce qui reflète un accroissement du pourcentage des cas nés outre-mer de $88,9 \%$ à $95,8 \%$ entre 2005 et 2010 ( $P=$ 0,03). Plus d'un tiers de l'ensemble des cas provient de patients venant d'Inde ou du Viet Nam. Dans les cas nés outre-mer, la durée médiane entre l'arrivée et le diagno- stic a été de 4 ans. La moitié de l'ensemble des diagnostics consiste en une maladie pulmonaire, parmi lesquels les frottis de Ziehl-Neelsen sont positifs dans $45,4 \%$. Le traitement est le plus fréquemment auto-administré $(76,9 \%)$, et un très petit nombre de patients ont été perdus de vue ou ont connu un échec de traitement $(1,1 \%)$. Un lien avec un autre cas confirmé par le laboratoire n'existe que dans $4,1 \%$ des cas. La TB à germes multirésistants reste rare $(1,7 \%$ des cas $)$.

CONCLUSIONS : Dans l'Etat de Victoria, la TB reste peu fréquente selon les niveaux mondiaux et continue à affecter de manière prédominante la population née outremer. Les stratégies actuelles de lutte contre la TB dans l'Etat de Victoria sont efficientes, mais un contrôle renforcé dans les pays à fardeau élevé améliorera également la lutte locale contre la TB.
MARCO DE REFERENCIA: El estado de Victoria en Australia.

O BJETIVO: Describir las características epidemiológicas de la tuberculosis (TB) y el programa de control de la enfermedad en el estado de Victoria entre el 2005 y el 2010.

MÉTODOS: Se llevó a cabo un análisis retrospectivo de los casos de TB confirmados por el laboratorio en Victoria entre el 2005 y el 2010. Se cotejaron los registros del laboratorio estatal de referencia de TB con los registros de notificación del Departamento de Salud, con el propósito de recoger los datos de laboratorio, demográficos, clínicos y de tratamiento.

RESULTADOS: La incidencia de TB aumentó de manera global, pero disminuyó en la población nacida en Australia, lo cual indica un aumento en la proporción de casos en personas nacidas en el extranjero de $88,9 \%$ a $95,8 \%$ entre el 2005 y el $2010(P=0,03)$. Los pacientes originarios de la India y Viet Nam representaron más de un tercio de todos los casos. En los casos de pacientes nacidos en el extranjero, la mediana del lapso entre la llegada al país y el diagnóstico fue 4 años. La mitad de todos los diagnósticos consistió en TB pulmonar, de los cuales el $45,4 \%$ presentó una baciloscopia positiva con Ziehl-Neelsen. La estrategia terapéutica más frecuente fue el tratamiento autoadministrado $(76,9 \%)$; muy pocos pacientes abandonaron el tratamiento o presentaron un fracaso terapéutico $(1,1 \%)$. Solo en un $4,1 \%$ de los casos se observó un vínculo con otro caso confirmado por el laboratorio. La frecuencia de TB multidrogorresistente permanece baja $(1,7 \%$ de casos).

CONCLUSIón: La tasa de TB en el estado de Victoria permanece baja comparada con los niveles mundiales y sigue afectando de manera desproporcionada a las poblaciones nacidas en el extranjero. Las estrategias vigentes de control de la enfermedad en este estado son eficaces, pero un refuerzo de las medidas en los países con alta carga de morbilidad por TB también mejoraría el control local de la enfermedad. 